\title{
XXII Международная Черняевская конференция по химии, аналитике и технологии платиновых металлов
}

\author{
Т. М.Буслаева, д.Х.Н., РТУ МИРЭА \\ К. Ю. Жижин, д.х. н., член-корр. РАН, ИОНХ РАН
}

\begin{abstract}
18-22 ноября 2019 года в Москве проходила XXII Международная Черняевская конференция по химии, аналитике и технологии платиновых металлов, которая была организована Институтом общей и неорганической химии РАН им. Н. С. Курнакова и МИРЭА - Российским технологическим университетом. Конференция состоялась при поддержке Министерства науки и высшего образования РФ, Российского фонда фундаментальных исследований (проект РФФИ № 19-03-20105), Екатеринбургского завода по обработке цветных металлов, ООО «КОРТЭК», Новосибирского аффинажного завода, Красноярского завода цветных металлов им. В.Н. Гулидова, АО «НПК «Суперметалл», НКЦ "Лабтест», ВМК «Оптоэлектроника».
\end{abstract}

Главная цель Конференции - обобщение результатов фундаментальных и прикладных исследований в области химии, аналитической химии, технологии платиновых металлов и золота, а также практического использования самих металлов, соединений и материалов на их основе. Участники обсуждали новые идеи и проекты, перспективы и общие тенденции развития платиновой отрасли.

Работало четыре секции:

- Секция 1. "Химия соединений платиновых металлов и золота";

- Секция 2. "Аналитическая химия платиновых металлов и золота";

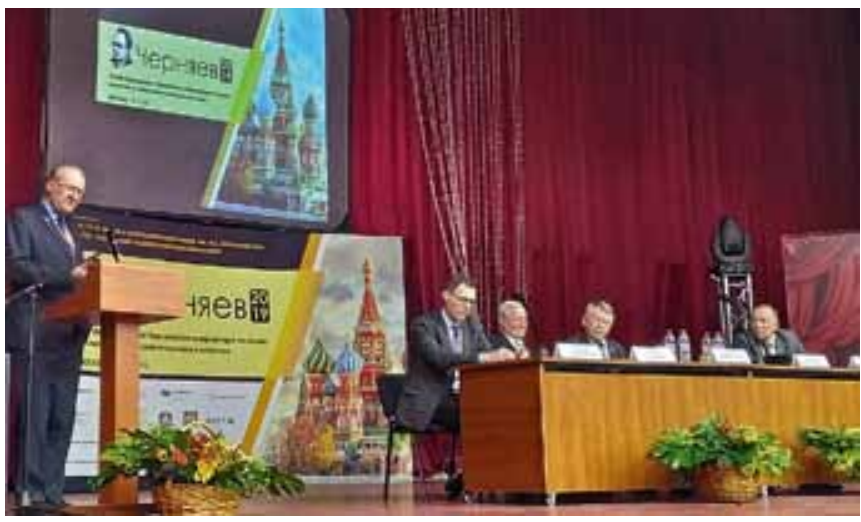

Академик Н. Т. Кузнецов открывает XXII Международную Черняевскую конференцию
- Секция 3. «Технология переработки сырья и производство платиновых металлов и золота";

- Секция 4. «Применение платиновых металлов и золота".

В работе конференции приняли участие 225 человек, представляющих вузы, научные организации и производственные предприятия из различных регионов РФ, ближнего и дальнего зарубежья. Среди участников - свыше 70 молодых ученых, аспирантов и студентов из крупнейших вузов страны (МГУ им. М. В. Ломоносова, Сибирский федеральный университет, Новосибирский государственный университет, РТУ МИРЭА и др.).

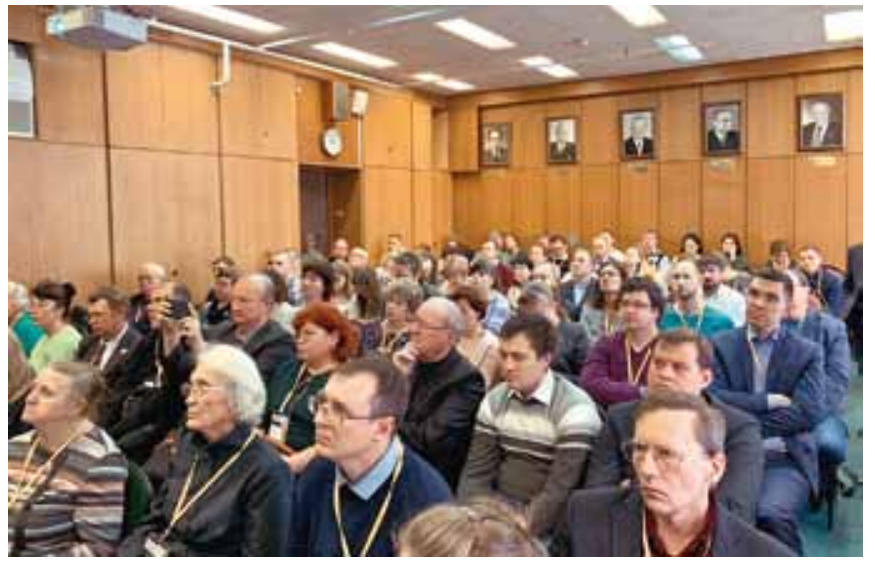

Участники пленарной сессии в ИОНХ РАН 
Всего было заслушано 15 пленарных докладов, 38 устных и 64 стендовых. Выступили с презентациями представители крупнейших аффинажных предприятий.

Особый интерес вызвали доклады по химии платиновых металлов, синтезу новых классов соединений (комплексы благородных металлов с полиоксометаллатами, хиральные орто-палладированные комплексы для катализа, семихинондииминовые комплексы платиновых металлов, комплексы с нитрильными лигандами). Были представлены сообщения о работах по использованию современных аналитических методов, методик, оборудования, в том числе и отечественного, для анализа различных объектов - от руды до материалов - и их методическому и метрологическому обеспечению. Отметим, что фундаментальные исследования по платиновым металлам призваны внести весомый вклад

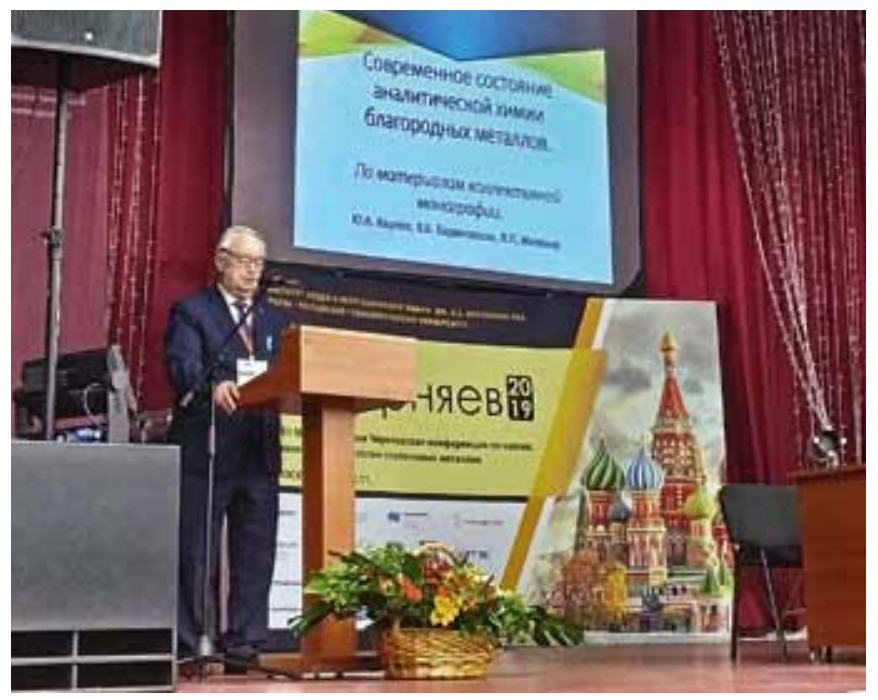

Академик Ю. А. Карпов выступает с пиенарным докиадом

\section{История конференции}

История платиновых совещаний насчитывает без малого восемь десятилетий. I Совещание было организовано в 1943 году в Свердловске (ныне - Екатеринбург) по инициативе руководства Государственного аффинажного завода и посвящалось преимущественно вопросам анализа благородных металлов. В 1945 году там же состоялось II Совещание, фактически с той же проблематикой, но уже с участием ведущих ученых страны И. И. Черняева, Н. К. Пшеницына, О. Е. Звягинцева, которые выступили с обзорными постановочными докладами по технологии, анализу и применению платиновых металлов. III Совещание прошло в Москве, в Институте общей и неорганической химии в 1954 году. В дальнейшем интервал между Совещаниями составлял три-четыре года: IV Совещание прошло в Свердловске в 1957 году, V - в Новосибирске в 1960 году, VI - в Красноярске в 1963 году. Все они назывались "Совещаниями по анализу благородных металлов": росла их представительность, но в центре внимания оставались проблемы анализа. И только в 1966 году на VII Совещании в Норильске в программу были включены вопросы химии и технологии благородных металлов. С того момента Совещания получили статус «Всесоюзных совещаний по химии, анализу и технологии благородных металлов": VIII (1969, Новосибирск), IX (1973, Красноярск), X (1976, Новосибирск). Начиная с 1979 года (ХІ Совещание, Ленинград) принято решение именовать все последующие совещания Черняевскими в честь особых заслуг академика Ильи Ильича Черняева. В рамках XII, XIII и XIV Совещаний (Москва, Свердловск и Новосибирск соответственно) на технологической секции обсуждались доклады с грифом "Для служебного пользования". На XIV Совещании впервые организована стендовая сессия. XV Черняевское совещание (1993, Москва, ИОНХ РАН им. Н. С. Курнакова) знаменательно тем, что оно было первым съездом платинистов, организованным в трудное постсоветское время. XVI (1996, Екатеринбург) и последующие Совещания по платиновым металлам стали Международными: - XVII (2001, Москва) и XVIII (2006, Москва). С2006 года они называются "Международная Черняевская конференция по химии, аналитике и технологии платиновых металлов". Успешно прошли XIX, XX и XXI Конференции в Новосибирске (2010), Красноярске (2013) и Екатеринбурге (2016)

За прошедшие годы сменилось не одно поколение ученых и инженеров, посвятивших свою жизнь уникальным элементам платиновой группы, для которых Черняевское совещание является знаковым событием, ицели его остаются неизменными: обобщение результатов фундаментальных и прикладных исследований в области химии, анализа, технологии, применения платиновых металлов и золота, соединений и материалов на их основе; обсуждение общих тенденций и перспектив их развития. 


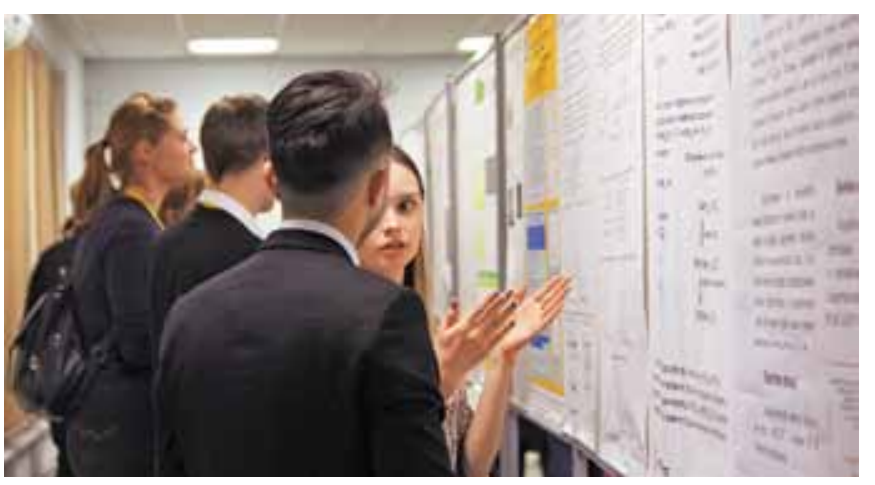

Обсуждение постерных докиадов

в практику, прежде всего, получения материалов с важными физическими и физико-химическими характеристиками.

Повышенное внимание обратили на себя доклады по практическому применению платиновых металлов, например противоопухолевые соединения рутения и увеличение их активности путем использования мишень-ориентированных лигандов; применение отечественных сплавов благородных металлов в стоматологии и т. п.

Уровень докладов по технологии платиновых металлов пока не соответствует современным химическим технологиям, хотя большинство отечественных разработок защищено патентами РФ и внедрено на предприятиях.

В рамках конференции заслушан доклад, посвященный 175-летию открытия рутения в России и многогранной деятельности выдающегося ученого Карла Карловича Клауса.

С успехом прошла постерная сессия, по итогам которой 10 молодых ученых удостоены дипломами за лучший постерный доклад и активное участие в работе Конференции.

Проведение следующей XXIII Черняевской конференции запланировано на 2022 в год Новосибирcke.

Сборник тезисов конференции размещен на http://chernyaev2019.ru/index.php/ru/programma.

\section{БИОИНЖЕНЕРЫ СОЗДАЛИ "УМНЫЕ" ПОВЯЗКИ ДЛЯ ЛЕЧЕНИЯ ХРОНИЧЕСКИХ РАН}

Исследователь из UConn (Коннектикутский университет, США) смог разработать новую «умную повязку", которая может улучшить оказание медицинской помощи при лечении хронических ран. Хронические и незаживающие раны - одно из самых разрушительных осложнений диабета и главная причина ампутации конечностей поражают миллионы людей по всему миру каждый год. Из-за сложной природы этих ран надлежащее клиническое лечение затруднительно. Впервые группа ученых отдела биомедицинской инженерии UConn разработала беспроводную, «умную» повязку и управляющую ею платформу

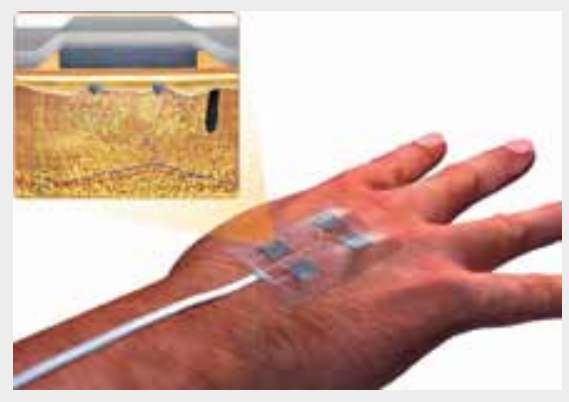

размером со смартфон. Эта система обеспечивает точную доставку различных лекарств к ране с необходимой дозировкой.

Повязка, разработанная доктором Али Тамайолом и его командой из Университета штата Небраска и Гарвардской медицинской школы, оснащена миниатюрными иглами, которые можно контролировать по беспроводному соединению, что позволяет программировать подачу лекарств дистанционно. "Это важный шаг в разработке передовых повязок, которые могут облегчить заживление трудно поддающихся лечению ран. Повязку не нужно постоянно менять", - говорит А. Тамайол. Учитывая спектр процессов, необходимых для заживления ран, на разных этапах регенерации тканей необходимы разные лекарства. Повязка - носимое устройство - может доставлять лекарства с минимальной инвазивностью.

С помощью «умной» повязки поставщик может дистанционно контролировать высвобождение нескольких лекарств, доставляемых через миниатюрные иглы. Эти иглы способны проникать в более глубокие слои раневого ложа с минимальными болями и воспалением. Этот метод оказался более эффективным для закрытия ран и роста волос по сравнению с местным введением лекарств, а также является минимально инвазивным.

Исследование, опубликованное в Advanced Functional Materials, было вначале проведено на клетках, а затем на диабетических мышах с повреждением кожи на полную ее толщину. С помощью этой технологии у мышей были обнаружены признаки полного заживления без образования рубцов, что свидетельствует о способности повязок значительно улучшить скорость и качество заживления ран у животных с диабетом.

Эти данные могут потенциально заменить существующие системы ухода за ранами и значительно снизить число больных с хроническими ранами. А. Тамайол подал заявку на патент для закрепления авторских прав на эту технологию.

По матерuаnam: https://phys.org 


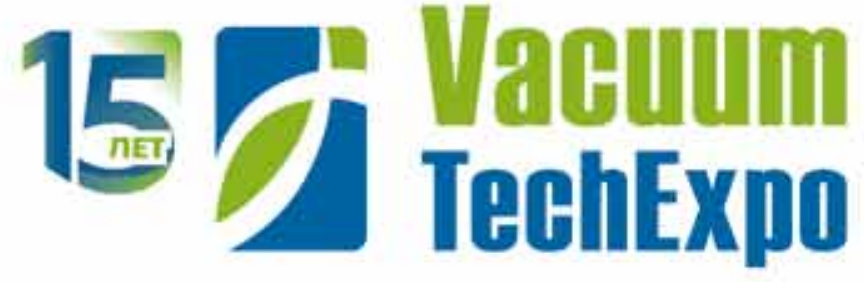

15-я Международная выставка

вакуумного и криогенного оборудования

14-16 апреля 2020

Москва, КВЦ «Сокольники»

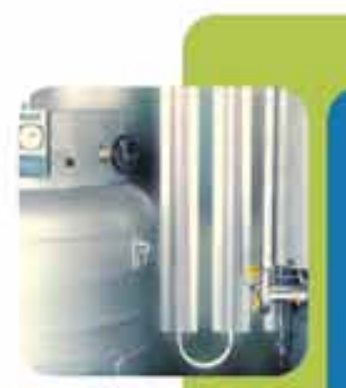

Единственная

в России выставка

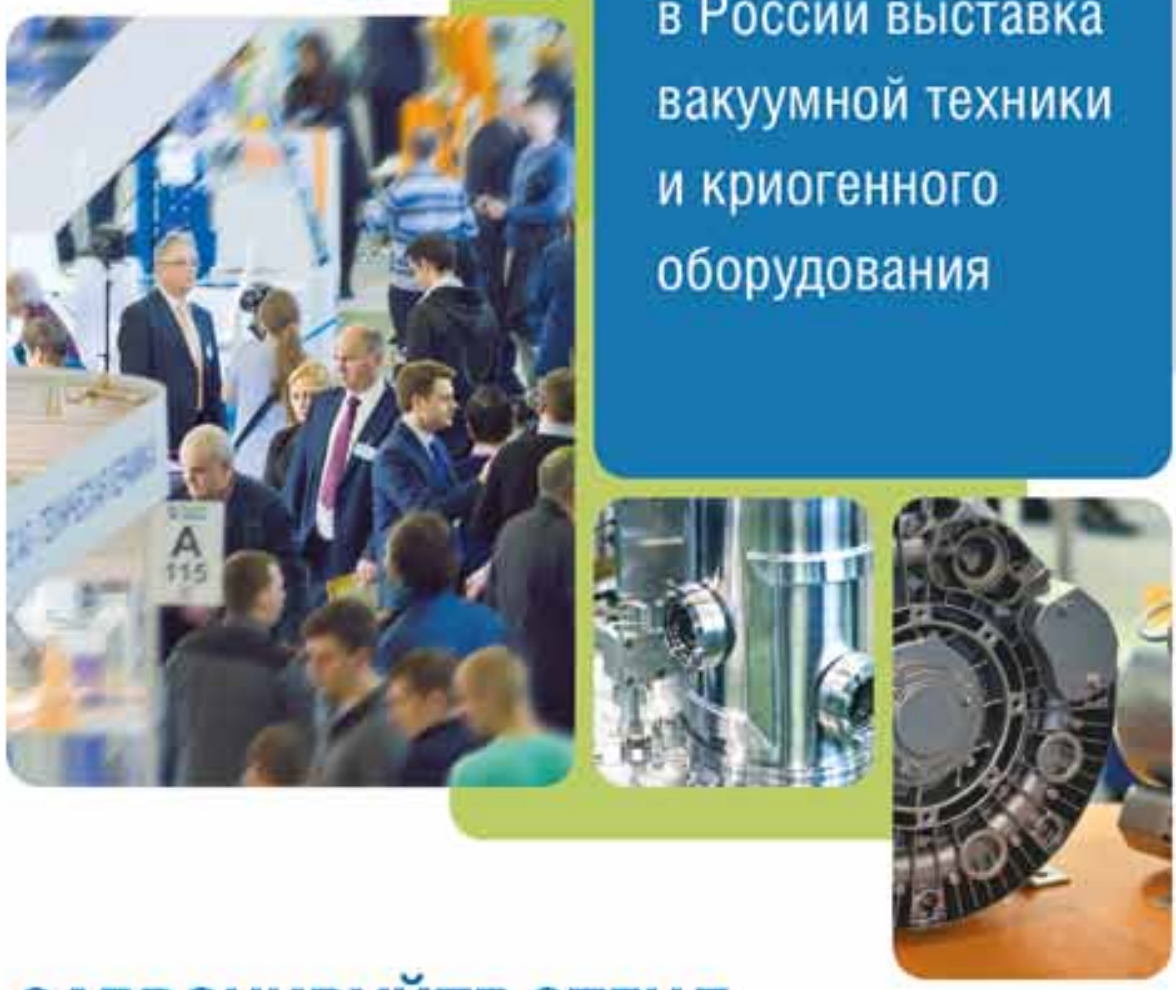

ЗАБРОНИРУЙТЕ СТЕНД

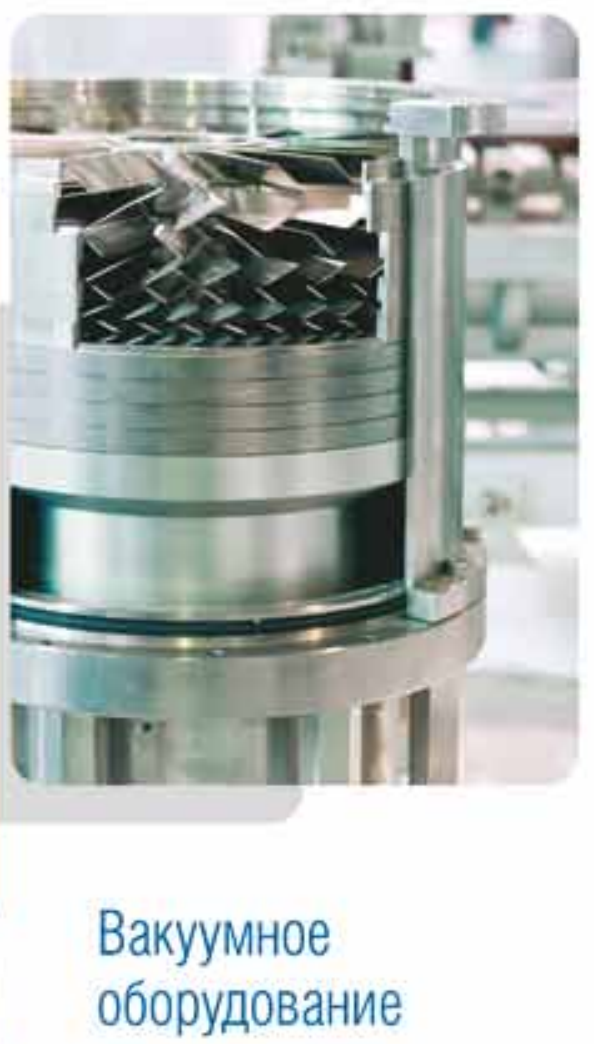

vacuumtechexpo.com

Криогенное

оборудование

Оборудование для нанесения функциональных покрытий 